\title{
Incidence and risk factors for ventricular septal defect in "low risk" neonates
}

\author{
A J Sands, F A Casey, B G Craig, J C Dornan, J Rogers, H C Mulholland
}

\begin{abstract}
Aims-To quantify the incidence of ventricular septal defect in "low-risk" neonates; and to define any associated risk factors.

Methods-One hundred and seventy three patients with ventricular septal defects from a scanned population of 3971 clinically normal neonates were compared with scanned controls, considered to be clinically normal. A subset of the group with defects was compared with normal infants delivered over the same period, to identify any seasonal variation.

Results-Ventricular septal defects were detected in $4.36 \%$ of the "scanned" group (173 out of 3971). Ten had perimembranous defects and the remainder apical or muscular lesions. Eleven neonates had multiple defects. The incidence of ventricular septal defect was independent of most tested risk factors. There were significantly more girls in the group with defects compared with the controls ( $p=$ $0.004)$. The defects group also contained fewer infants born during summer months $(p=0.04)$.

Conclusions-The incidence of ventricular septal defects was much higher than might be expected, given that "high risk infants" were excluded. The observations that gender and season of birth affect the rate suggest that both genetic and environmental factors may be involved in the aetiology.

(Arch Dis Child Fetal Neonatal Ed 1999;81:F61-F63)
\end{abstract}

Keywords: ventricular septal defect; risk factors

Ventricular septal defects are the most common form of congenital heart disease and among the most frequently seen congenital abnormalities. Prevalence is higher in neonates than it is in older children due to the rate of spontaneous closure. A closure rate of $50-75 \%$ has been cited for small defects among older children. About 10 years ago the overall rate of congenital heart disease seemed to be increasing, because of a rise in the numbers of ventricular septal defects diagnosed. ${ }^{1-4}$ The consensus was that any increase could be explained on the basis of better detection, particularly using colour flow Doppler. ${ }^{15}$

In this study ventricular septal defects were not sought exclusively, but examination of the ventricular septum was part of each assessment. Two notable studies in recent years have used colour Doppler interrogation, solely to identify muscular defects. ${ }^{6}$ An exceptionally high prevalence was found in both term and preterm infants. This study broadly supports these findings, although the populations under investigation were not entirely comparable. ${ }^{1}$

\section{Methods}

Each year around 2600 babies are born in the Royal Maternity Hospital, Belfast (the regional maternity and neonatal unit). This represents about one tenth of the Northern Ireland total. Since November 1994 deliveries at this institution have been randomly assigned to one of two groups. The first group received an echocardiographic assessment (with parental consent) in addition to clinical examination(s). The second group received only clinical examination. Infants were not scanned unless they had at least one normal clinical examination.

Infants with ventricular septal defects were managed according to clinical need. As most defects were small and the infants were otherwise well, management typically entailed a 6 month review with repeat echocardiography and physical examination, as required. Those with more clinically significant lesions were examined by a paediatric registrar or senior house officer and managed with referral to the regional paediatric cardiology service. Most of these infants were also examined by a consultant paediatric cardiologist before discharge or kept in hospital for further assessment or treatment.

Mothers approaching delivery with the following features were excluded from scanning.

- Insulin dependent diabetes mellitus ( $n=29)$

- Strong family history of congenital heart disease: (usually fatal or surgically treated congenital heart disease in a first degree relative) $(\mathrm{n}=7)$

- Detected antenatal abnormality relating to the cardiovascular system $(\mathrm{n}=7)$

- Intrauterine death $(n=18)$

The following exclusions were applied to infants.

- Down's syndrome $(n=6)$

- Stillbirth $(n=49)$

- Perinatal death $(n=13)$

- Admission to special care baby unit $(n=471)$

- Detection of postnatal abnormality relating to the cardiovascular system $(\mathrm{n}=7)$; note crossover with special care baby unit admissions

- Mother refused scan $(n=48)$

- "Domino" delivery - with discharge occurring 6 hours after delivery $(n=34)$

- Other early discharge $(n=93)$

The birthweight and gestation were noted for all infants. Maternal age at delivery and booking details such as previous obstetric 
Table 1 Effects of gender and risk factors

\begin{tabular}{lllll}
\hline Risk factor & No in defects group & No in control group & p Value & Odds Ratio \\
\hline Smoking & $41 / 173(23.7 \%)$ & $39 / 139(28.1 \%)$ & 0.381 & $0.8(0.48-1.33)$ \\
Alcohol & $18 / 173(10.4 \%)$ & $20 / 139(14.4 \%)$ & 0.285 & $0.69(0.35-1.36)$ \\
Low parity & $76 / 173(43.9 \%)$ & $58 / 142(40.8 \%)$ & 0.501 & $1.13(0.72-1.78)$ \\
Miscarriage & $34 / 173(19.7 \%)$ & $23 / 142(16.2 \%)$ & 0.420 & $1.27(0.71-2.27)$ \\
Female & $84 / 173(48.6 \%)$ & $60 / 142(42.3 \%)$ & 0.002 & $2.06(1.31-3.23)$ \\
\hline
\end{tabular}

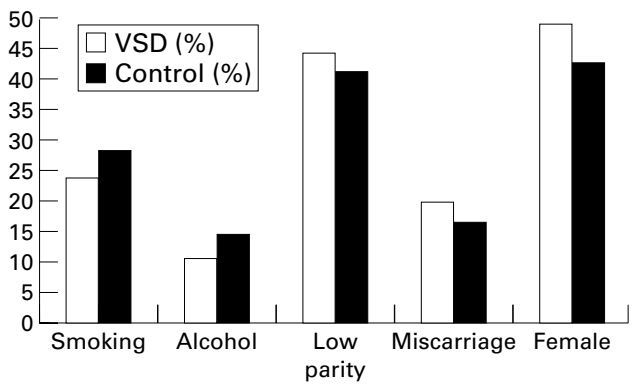

Figure 1 Effect of maternal history of smoking, alcohol consumption, low parity and previous miscarriage.

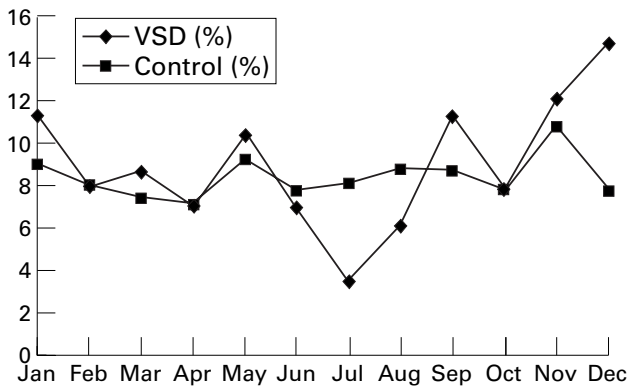

Figure 2 Month of delivery of infants in septal defects and control groups.

history, cigarette and alcohol consumption, were also recorded. Studies were performed using an ATL Ultramark 9 or an ATL Apogee cx. Most review scans were performed using an Ultramark 9 or ATL HDI 3000. All echocardiograms were performed by, or under the supervision of, sonographers experienced in paediatric echocardiography.

\section{Results}

Of 3971 scans performed between 1 November 1994 and 28 February 1998, 173 infants $(4.36 \%)$ had ventricular septal defects. Only infants with an entirely normal echocardiogram were included in a group from which controls were selected at random.

$\chi^{2}$ analysis was used to assess the effect of a positive maternal history of smoking, alcohol consumption, low parity and previous miscarriage. The effect of infant gender was similarly assessed. The $M: F$ ratio of infants scanned was 1.02:1. These data are summarised in table 1 and fig 1.

The effect of maternal age, birthweight, and gestational age was assessed using a two tailed Student's $t$ test. The mean maternal age at

Table 2 Effect of seasonal variation on vascular defects

\begin{tabular}{lllll}
\hline & $\begin{array}{l}\text { Spring } \\
\text { (March-May) }\end{array}$ & $\begin{array}{l}\text { Summer } \\
\text { (Fune-Aug) }\end{array}$ & $\begin{array}{l}\text { Autumn } \\
\text { (Sept-Nov) }\end{array}$ & $\begin{array}{l}\text { Winter } \\
\text { (Dec-Feb) }\end{array}$ \\
\hline Vascular defects & 30 & 19 & 36 & 31 \\
Control & 479 & 499 & 553 & 502 \\
\hline
\end{tabular}

delivery in the group with defects was 29.152 (0.84 95\% confidence interval) years and 29.008 (1.33 CI) years in the control group; $\mathrm{z}$ $=0.25, \mathrm{p}=0.4$. The mean birthweight in the defects group was $3417 \mathrm{~g}$ (80.24 CI) compared with $3330.3 \mathrm{~g}$ (85.94 CI) in the control group; $\mathrm{z}=0.04, \mathrm{p}=0.48$. Mean gestational ages for the two groups were: ventricular septal defects 39.43 weeks $(0.24 \mathrm{CI})$ and controls 39.12 weeks $(0.26 \mathrm{CI}) ; \mathrm{z}=1.28, \mathrm{p}=0.1$.

These data show that neither maternal smoking, alcohol consumption, nor maternal age are risk factors for ventricular septal defect. Several authors claim that these defects are more common in preterm infants. However, in common with other recent work, our study found no such link between gestational age and the risk of ventricular septal defects. In fact, the mean gestational age in the group with defects is greater than that of the controls and approaches statistical significance. However, recording of gestation was in completed weeks only and therefore rather imprecise. It should be remembered that infants whose gestational age necessitated admission to the special care baby unit were excluded from this work. The impression that mothers of children with ventricular septal defects are of lower parity and have a higher incidence of miscarriage does not reach the required probability level.

The month of delivery of infants in the defects and control groups is shown in fig 2 . In this instance infants with septal defects over the 24 months (November 1994 to November 1996) were compared with all infants scanned and found to have no ventricular septal defects during the same period.

The months of June, July, and August yielded a significantly smaller number of infants with ventricular septal defects. The seasonal variations in incidence are shown in table 2.

\section{Discussion}

Ventricular septation is usually complete by the end of the sixth intrauterine week. ${ }^{8}$ It is believed that the formation of the trabecular septum is rather different from the membranous portion. The fusion of the embryonic inlet septum and the trabecular area is an integral part of embryonic septation, but development of the constituent portions of the septum is usually synchronous, and factors affecting the development of one portion might reasonably be expected to affect both.

In his review of the aetiology of ventricular septal defects, Newman points out that the incidence is considered to be remarkably consistent worldwide. ${ }^{9}$ However this can be corroborated only if equivalent investigation techniques are used-colour Doppler-for example, as it is now clear that many defects may go undetected in the neonatal period. Genetic factors do seem to play a part, with an an increased risk of congenital heart disease for first degree relatives of children with ventricular septal defects (2-3\% compared with $0.6-1 \%$ for the population as a whole). Despite this, it is striking to note the reportedly high degree of discordance even between mono- 
zygotic twins. ${ }^{10}$ This study has limited the degree of genetic influence because of its exclusion criteria.

Attention has focused on environmental factors. It has been said that twin discordance for septal defect makes intrauterine insults less likely as aetiological factors. This is also seen in animals - similarly affected fetuses may not respond to teratogens in the same way. However, the degree of discordance may be partly explained by less sensitive detection methods.

Although maternal alcoholism does seem to cause ventricular septal defects and other forms of congenital heart disease, this study, in line with others, did not find any association between a positive history of alcohol consumption and the risk of defects. ${ }^{6}$ No attempt was made to categorise mothers further according to quantities of alcohol consumed. Maternal smoking, a risk factor investigated by several groups, again yielded a negative result Again, the actual number of cigarettes smoked was not assessed as figures may well lack accuracy.

Few cardiac teratogens have been identified in humans. This contrasts with the animal world where septal defects can be induced by the injection of various substances, such as herbicides. ${ }^{11}$ Administration of sex hormones has been linked to septal defects and other congenital heart disease. Although not significant, there was a difference between the defects group and controls in terms of maternal obstetric history. Reproductive history seemed to be worse in the defects group. It may be that differing levels of maternal hormones are important. Maternal age showed no difference across the two groups, a finding supported by other workers. ${ }^{6712}$. In this study female gender was associated with an increased risk of defects when compared with a control group of infants with an entirely normal scan. The control group in this instance might have been depleted of girls because of other minor defects. Although not significant, some difference has been documented by other authors dealing specifically with muscular ventricular septal defects. ${ }^{1}$ Seasonal variations in the birth of children with septal defects might imply the influence of teratogens, such as infection or atmospheric pollution. Summarising the pooled data from several studies, Newman found no link between ventricular septal defect and season. ${ }^{9}$ However, this work was again carried out before the routine use of echocardiography and Doppler ultrasonography. In contrast to other studies, our data clearly suggest that summer birth confers some protection from ventricular septal defect. This implies that is could be advantageous to conceive in September to November, as cardiac septation would then occur during autumn or early winter. This phenomenon is not easily explained on the basis of an absent infective agent or indeed reduced air pollution at this time of year. It seems likely, therefore, that other, less obvious factors are involved.
It has been suggested that muscular ventricular septal defects arise from cell death within an already formed ventricular septum while perimembranous defects may be the result of failed fusion secondary to transient interruption of the blood supply to the developing septum. ${ }^{13}$ Fetal echocardiography suggests that some small septal defects may close in utero. ${ }^{14}$ However, it seems less likely that they should form within an intact septum except perhaps in the presence of local ischaemia. Most authors agree that the aetiology of congenital ventricular septal defect is most likely multifactorial. The genetic component may well be quite weak.

Many would argue that small, muscular septal defects are of limited importance and as such do not merit diagnosis. However, if they reflect exposure to environmental teratogens, or help identify other influences harmful to the fetus, their true importance may lie in their role as markers of such an insult. It may also be that reproductive ability (maternal or perhaps paternal) is inversely related to the risk of ventricular septal defects, although the case is far from proved. Recently attention has focused on how an adverse intrauterine environment may leave an imprint on the individual for life, in terms of cardiovascular and other disease in later life. ${ }^{15}$ The case for ventricular septal defect as a marker of unrecognised intrauterine stress remains speculative. Long term follow up of a cohort such as this may well be productive.

1 Martin GR, Perry LW, Ferencz C. Increased prevalence of ventricular septal defect: epidemic or improved diagnosis. Pediatrics. 1989;83:200-3

2 Anderson CE, Edmonds LD, Erickson JD. Patent ductus arteriosus and ventricular septal defect: trends in reported frequency. Am ₹ Epidemiol 1978;107:281-9.

3 Layde PM, Dooley K, Erickson JD, Edmonds LD. Is there an epidemic of ventricular septal defects in the USA? Lancet 1980; 8165:407-8.

4 4Spooner EW, Hook EB, Farina MA, Shaher RM. Evaluation of a temporal increase in ventricular septal defects: estimated prevalence and severity in northeastern New York, 1970-1983. Teratology 1988;37:21-8.

5 Meberg A, Otterstad JE, Froland G, Sorland S, NitterHauge S. Increasing incidence of ventricular septal defects caused by improved detection rate. Acta Paediatrica 1994;83:653-7.

6 Roguin N, Du ZD, Barak M, Nasser N, Hershkowitz S, Milgram E. High prevalence of muscular ventricular septal defects in neonates. $\mathcal{F}$ Am Coll Cardiol 1995;26:1545-8.

7 Du ZD, Roguin N, Barak M, Bihari SG, Ben-Elisha M. High Prevalence of muscular ventricular septal defect in preterm neonates. Am $\mathcal{F}$ Cardiol 1996;78:1183-5.

8 Anderson RH, Becker AE. The development of the heart. In: Cardiac anatomy: an integrated text and colour atlas. LonIn: Cardiac anatomy: an integrated text and colo

9 Newman TB. Epidemiology of ventricular septal defects: an epidemiologic approach. Pediatrics 1985;76:741-9.

10 Anderson RC. Congenital cardiac malformations in 109 sets of twins and triplets. Am f Cardiol 1977;39:1045-50.

11 Kawamura S, Yoshioka T, Kato T, Matsuo M, Yasuda M. Histological changes in rat embryonic blood cells as a possible mechanism for ventricular septal defects produced by an N-phenylimide herbicide. Teratology 1996;54:237-44.

12 Tikkanen J, Heinonen OP. Risk factors for ventricular septal defect in Finland. Public Health 1991;105:99-112.

13 Clarke E. Mechanisms in the pathogenesis of congenital cardiac malformations. In: Pierpont $\mathrm{M}$, Moller J, eds. Genetics of cardiovascular disease. Boston: Martinus Nijhoff 1987: 3-11.

14 Orie J, Flotta D, Sherman FS. To be or not to be a VSD. Am 7 Cardiol 1994;74:1284-5.

15 Rich-Edwards JW, Stampfer MJ, Manson JE, et al. Birth weight and risk of cardiovascular disease in a cohort of women followed up since 1976. BMF 1997;395:396-400. 